\title{
The role of attentional bias in obesity and addiction
}

Citation for published version (APA):

Field, M., Werthmann, J., Franken, I., Hofmann, W., Hogarth, L., \& Roefs, A. (2016). The role of attentional bias in obesity and addiction. Health Psychology, 35(8), 767-780.

https://doi.org/10.1037/hea0000405

Document status and date:

Published: 01/08/2016

DOI:

10.1037/hea0000405

Document Version:

Publisher's PDF, also known as Version of record

Document license:

Taverne

Please check the document version of this publication:

- A submitted manuscript is the version of the article upon submission and before peer-review. There can be important differences between the submitted version and the official published version of record.

People interested in the research are advised to contact the author for the final version of the publication, or visit the DOI to the publisher's website.

- The final author version and the galley proof are versions of the publication after peer review.

- The final published version features the final layout of the paper including the volume, issue and page numbers.

Link to publication

\footnotetext{
General rights rights.

- You may freely distribute the URL identifying the publication in the public portal. please follow below link for the End User Agreement:

www.umlib.nl/taverne-license

Take down policy

If you believe that this document breaches copyright please contact us at:

repository@maastrichtuniversity.nl

providing details and we will investigate your claim.
}

Copyright and moral rights for the publications made accessible in the public portal are retained by the authors and/or other copyright owners and it is a condition of accessing publications that users recognise and abide by the legal requirements associated with these

- Users may download and print one copy of any publication from the public portal for the purpose of private study or research.

- You may not further distribute the material or use it for any profit-making activity or commercial gain

If the publication is distributed under the terms of Article $25 \mathrm{fa}$ of the Dutch Copyright Act, indicated by the "Taverne" license above, 


\title{
The Role of Attentional Bias in Obesity and Addiction
}

\author{
Matt Field \\ University of Liverpool and the UK Centre for Tobacco and \\ Alcohol Studies (UKCTAS) \\ Ingmar Franken \\ Erasmus University Rotterdam
}

Lee Hogarth
University of Exeter

\author{
Jessica Werthmann \\ Kings College London
}

Wilhelm Hofmann
University of Cologne

Anne Roefs

Maastricht University

\begin{abstract}
Objectives: The purpose of this article is to critically evaluate the following claims derived from contemporary theoretical models of attentional bias $(\mathrm{AB})$ for food- and drug-related stimuli: (a) $\mathrm{AB}$ is a characteristic feature of obesity and addiction, (b) $\mathrm{AB}$ predicts future behavior, (c) AB exerts a causal influence on consummatory behavior, and (d) AB reflects appetitive motivational processes. Method: A focused discussion of the relevant literature is presented. Results: The available evidence reveals inconsistencies with the aforementioned claims. Specifically, AB is not consistently associated with individual differences in body weight or drug use, $\mathrm{AB}$ does not consistently predict or influence distal consummatory behavior, and $\mathrm{AB}$ may be influenced by both appetitive and aversive motivational processes. These insights are synthesized into a theoretical account that claims that $\mathrm{AB}$ for food- and drug-related stimuli arises from momentary changes in evaluations of those stimuli that can be either positive (when the incentive value of the food or drug is high), negative (when individuals have a goal to change their behavior, and those stimuli are perceived as aversive), or both (when individuals experience motivational conflict, or ambivalence). Conclusions: The proposed theoretical synthesis may account for the contributions of appetitive and aversive motivational processes involved in selfregulatory conflicts to $\mathrm{AB}$, and it yields testable predictions about the conditions under which $\mathrm{AB}$ should predict and have a causal influence on future consummatory behavior. This has implications for the prediction and modification of unhealthy behaviors and associated disorders.
\end{abstract}

Keywords: ambivalence, attentional bias, conflict, craving, evaluation

Individual differences in both appetitive and aversive motivation are associated with attentional bias $(\mathrm{AB})$ for salient environmental cues. Regarding appetitive motivation, substance use disorders (addiction) and obesity, and subjective states of craving and hunger, are associated with $\mathrm{AB}$ for drug- and food-related stimuli, respectively (Field \& Cox, 2008; Werthmann, Jansen, \& Roefs, 2015). Regarding aversive motivation, individuals with anxiety disorders, and people in an anxious state, have an $\mathrm{AB}$ for threat-

Matt Field, Department of Psychological Sciences, University of Liverpool, and the UK Centre for Tobacco and Alcohol Studies (UKCTAS); Jessica Werthmann, Institute of Psychiatry, Psychology and Neuroscience, Kings College London; Ingmar Franken, Institute of Psychology, Erasmus University Rotterdam; Wilhelm Hofmann, Department of Psychology, University of Cologne; Lee Hogarth, School of Psychology, University of Exeter; Anne Roefs, Faculty of Psychology and Neuroscience, Maastricht University.

Correspondence concerning this article should be addressed to Matt Field, Department of Psychological Sciences, University of Liverpool, Eleanor Rathbone Building, Bedford Street South, Liverpool, L69 7ZA, United Kingdom. E-mail: mfield@liv.ac.uk ening stimuli in their environment (Cisler \& Koster, 2010). This paper presents a critical discussion of the relationship between appetitive motivation and $\mathrm{AB}$, with a focus on addiction and obesity.

First, an overview of theoretical models of $\mathrm{AB}$ is provided and their shared predictions are highlighted, namely (a) AB should be most pronounced in people who are addicted or obese, (b) AB predicts future behavior, (c) $\mathrm{AB}$ exerts a causal influence on behavior, and (d) $\mathrm{AB}$ reflects appetitive motivational processes. This is followed by a focused review of the relevant literature in which findings that that are compatible and incompatible with these predictions are discussed. A number of important observations are highlighted, including inconsistent cross-sectional and prospective associations between $\mathrm{AB}$ and individual differences in body weight and drug use, unconvincing evidence for a causal influence of $\mathrm{AB}$ on behavior, and demonstrations that both appetitive and aversive motivational processes appear to influence $A B$.

In the final part of the paper, we synthesize these observations and propose a novel account of $\mathrm{AB}$ in obesity and addiction. The central claims of this account are that (a) $A B$ is primarily determined by current evaluations of drug-and food-related cues, and those evaluations can be positive or negative, or both simultane- 
ously (ambivalence), (b) the stability and predictive validity of $\mathrm{AB}$ and its causal influence on behavior have been overstated, and (c) the sensitivity of $\mathrm{AB}$ to the current motivational state and conflicting goals have been underappreciated.

\section{Definition and Measurement of Attentional Bias}

$\mathrm{AB}$ can be defined as the tendency for specific types of stimuli (here, drug- and food-related pictures and words, hereafter referred to as "substance cues") to capture and/or hold the attention. Detailed descriptions of $\mathrm{AB}$ methods and their limitations are available elsewhere (Field \& Cox, 2008; Field \& Franken, 2014; Nijs \& Franken, 2012; Werthmann, Jansen et al., 2015; Yiend, 2010), and a brief description of the most commonly used methods is provided here.

In the modified Stroop task, words are presented in different colors and participants are required to identify the color of the words while ignoring their meaning. If participants are slower to identify the color of one category of words (e.g., food-related words) than another (e.g., office-related words), the inference is that the former category of words captured the attention and interfered with color naming.

In the visual probe task (and other types of attentional cueing tasks), a pair of words or pictures is briefly presented on a computer screen before a visual "probe" (e.g., a small arrow) appears in the location that had been occupied by one of the stimuli. Participants are instructed to respond to the probe as rapidly as possible, and if reaction times (RTs) are consistently faster to probes that replace one type of stimulus (e.g., pictures of cigarettes) compared to another (e.g., pictures of pencils), the inference is that participants' attention was directed at the former objects just before the probe appeared (Yiend, 2010). An appealing feature of the task is that, unlike the Stroop task, RTs from the visual probe task can distinguish between $\mathrm{AB}$ for a certain category of stimuli (e.g., smoking-related pictures) and attentional avoidance of those stimuli; that is a bias to direct attention away from those stimuli rather than toward them. Attentional avoidance, which can be thought of as a special type of $A B$, is inferred if participants are faster to respond to probes that replace control stimuli rather than probes that replace substance-related stimuli (Yiend, 2010).

Finally, electroencephalography (EEG) can be used to measure attentional processing of motivationally salient stimuli. In a typical task, images are individually presented on a computer screen for several seconds while scalp-mounted electrodes record eventrelated potentials (ERPs) that are evoked by the stimuli. Some components of the ERP, in particular the P300 and the slow potential, are associated with allocation of attention to those stimuli ("motivated attention"; Schupp et al., 2004). Therefore their amplitude in response to motivationally salient versus control pictures is interpreted as a marker of AB (Littel, Euser, Munafò, \& Franken, 2012).

There are methodological issues with all of these measures. First, both the modified Stroop task and ERPs yield outcome measures that are difficult to interpret: Identical patterns of Stroop interference are produced by appetitive and aversive words, and therefore any observed $\mathrm{AB}$ in the task may arise because words are evaluated positively or negatively, or both (Yiend, 2010). Similarly, the P300 and slow potential components of the ERP cannot distinguish between appetitive and aversive responses to the stimuli (Briggs \& Martin, 2009; Little et al., 2012; Polich, 2007). Second, each of these tasks can be influenced by cognitive strategies that participants might employ in an attempt to suppress $\mathrm{AB}$ (Yiend, 2010; Littel \& Franken, 2011; Meule, Kübler, \& Blechert, 2013). Finally, RT indices of AB derived from the modified Stroop and visual probe tasks are limited by poor internal reliability (Ataya et al., 2012; Van Bockstaele et al., 2014). Fortunately, more reliable (and direct) indices of $\mathrm{AB}$ may be obtained by monitoring participants' eye movements as they complete the visual probe task (Christiansen, Mansfield, Duckworth, Field, \& Jones, 2015).

\section{Existing Theoretical Models of AB and Their Predictions}

This section provides a brief overview of theories of addiction and obesity that posit a role for $\mathrm{AB}$ for substance cues, and highlights predictions that are shared by these theories. The discussion is limited to theories that have provided the impetus for research on $\mathrm{AB}$ in addiction and obesity, but other relevant theories are discussed later in the paper. Arguably most influential is the incentive-sensitization theory (IST) of drug addiction proposed by Robinson and Berridge (1993). The central tenet of this theory is that consumption of drugs increases dopamine transmission in reward-related regions of the brain (specifically, the nucleus accumbens and other structures that form the mesolimbic dopamine system), and this dopamine response becomes sensitized (it progressively increases) with each episode of drug consumption. The resulting sensitized dopamine activity in the reward system increases the motivational appeal of the drug, and the subjective corollary of this is subjective craving. Through an associative learning process, drug-related cues acquire strong motivational properties (incentive salience) and as a consequence those cues "grab attention, become attractive and wanted, and thus guide behavior to the incentive" (Robinson \& Berridge, 1993, p. 261).

The IST was originally proposed to account for dopamine adaptations in response to addictive drugs and in its original formulation, sensitization processes were proposed to occur only for addictive drugs but not for other, "natural" rewards such as food. However, subsequent work on the nature of brain adaptations in obesity, including by one of the original proponents of IST (Berridge, 2009) prompted the development of theories that propose that identical processes occur as a consequence of repeated consumption of food. For example, Nijs and Franken (2012) stated that

neurocognitive addiction models, such as the (IST) might be applicable to obesity. This means that, similar to addiction, an attention bias to rewarding foods might play an important role in the development and maintenance of overeating behavior and weight gain/obesity. (p. 107; see also Volkow \& Wise, 2005)

Similarly, a recent temptation management model of obesity treatment proposed that "for obese individuals participating in lifestyle interventions, palatable food may act as a 'motivational magnet' that monopolizes attention and triggers lapses in diet adherence" (Appelhans, French, Pagoto, \& Sherwood, 2016, p. 270).

The term craving refers to a "drug acquisitive motivational state" (Baker, Morse, \& Sherman, 1986, p. 258), which is synonymous with "desire", an "affectively charged motivation ... the 
feeling of wanting to have or do something (that) motivates behavior" (Hofmann \& Van Dillen, 2012, p. 317). The theories discussed above claim that subjective craving/desire should be closely associated with the magnitude of $\mathrm{AB}$. This prediction was refined by subsequent theories, initially Franken's cognitive psychopharmacological model (Franken, 2003) and subsequently by the Elaborated Intrusion (EI; Kavanagh, Andrade, \& May, 2005) and the Dynamical models (Hofmann \& Van Dillen, 2012) of desire. These theories posit that craving and $\mathrm{AB}$ are both outputs of an underlying appetitive motivational process. Importantly, they diverge from earlier predictions (such as those made by IST) by claiming that, once activated, each can increase the strength of the other until a threshold is crossed, at which point the person "gives in to temptation" and consumes the substance.

Several predictions are common to each of these theories. First, $\mathrm{AB}$ for substance cues develops as a consequence of associative learning and once established, it should be a long-lasting characteristic. Therefore, AB for drug-related cues should be present in all drug users but most pronounced in those with more frequent exposure to the drug, that is, heavy users with more severe addiction. Regarding $\mathrm{AB}$ for food stimuli, most people have experience of eating food, so $\mathrm{AB}$ for food should be present in almost everybody to some degree (Werthmann, Roefs, Nederkoorn, Mogg et al., 2013). However, given that obesity is primarily attributable to overeating (Cecil et al., 2012), AB for food stimuli should be most pronounced in people who are obese (see Nijs \& Franken, 2012 and Appelhans et al., 2016, who make this claim explicitly).

The second shared prediction is that individual differences in $\mathrm{AB}$ should predict future behavior, in particular the probability of seeking out and consuming that substance, the amount consumed, or the likelihood of relapse to drug use, or weight gain (due to increased food intake) after treatment. The third shared prediction is that, in addition to being predictive, $\mathrm{AB}$ has a causal influence on consummatory behavior (i.e., eating and drug use). The fourth and final shared prediction is that $\mathrm{AB}$ reflects an underlying appetitive motivational process, and therefore it should be strongly correlated with subjective craving or desire for the substance.

In the following sections of this paper, each of these predictions is critically evaluated. The evidence base is large, and it is beyond the scope of the present paper to provide an exhaustive review (for comprehensive reviews of this literature, see Doolan, Breslin, Hanna, \& Gallagher, 2014; Field \& Cox, 2008; Leeman, Robinson, Waters, \& Sofuoglu, 2014; Nijs \& Franken, 2012; Werthmann, Jansen et al., 2015).

\section{Prediction 1: Is AB Stronger in People Who Are Addicted or Obese, Compared to Those Who Are Not?}

This prediction can be evaluated with reference to reviews and meta-analyses of studies that reported between-groups comparisons in $\mathrm{AB}$ between addicted or obese samples and controls. First, regarding $\mathrm{AB}$ for drug-related cues, meta-analyses have confirmed that $\mathrm{AB}$ for drug-related cues (including alcohol and tobacco cues) is larger in users versus nonusers of those drugs (e.g., smokers vs. nonsmokers) when the modified Stroop task (Cox, Fadardi, \& Pothos, 2006) and ERP measures (Littel et al., 2012) are used to measure AB. Regarding the visual probe task, narrative reviews of studies that used this and related tasks (Field \& Cox, 2008; Field,
Marhe, \& Franken, 2014), sometimes in combination with eye movement monitoring, confirmed the presence of $\mathrm{AB}$ in users versus nonusers of those drugs. However, within addict groups, the associations between $\mathrm{AB}$ and individual differences in the quantity or frequency of tobacco smoking and alcohol consumption are inconsistent (Field \& Cox, 2008). For example, on the visual probe task, some studies report that $\mathrm{AB}$ is stronger in heavy (more frequent) smokers, whereas others report the opposite (e.g., Mogg, Field, \& Bradley, 2005; Vollstadt-Klein et al., 2011). Other studies that used the task demonstrated attentional avoidance or an "approach-avoidance" (ambivalent) pattern of AB in alcoholdependent patients who were undergoing treatment, relative to nondependent controls: initial orienting of attention toward alcohol stimuli followed by the shifting of attention away from those stimuli (reviewed in Field, Mogg, Mann, Bennett, \& Bradley, 2013).

Narrative reviews of the literature on food-related $A B$ in obese and normal-weight participants concluded that findings have been very inconsistent, in the sense that the nature of group differences varied across studies. For example, Werthmann, Jansen et al. (2015) noted that of 11 published studies, some reported that $A B$ was positively associated with obesity and overweight, others reported the opposite (smaller $\mathrm{AB}$ in overweight and obese participants), and others reported no difference (see also Doolan et al., 2014; Nijs \& Franken, 2012). An observation may clarify the relationship between $\mathrm{AB}$ and obesity: if participants were tested in a hungry state this tended to mask between-groups differences, but $\mathrm{AB}$ was larger in obese compared to normal weight participants if participants were sated at the time of testing (Castellanos et al., 2009; Nijs, Muris, Euser, \& Franken, 2010). One explanation is that ceiling effects in $\mathrm{AB}$ when people are hungry may mask between-groups differences, an issue that is revisited later in this paper.

In summary, the addiction literature is partly consistent with theoretical predictions because $\mathrm{AB}$ for drug cues is larger in drug users versus nonusers, and this effect is robust. However, contrary to theoretical predictions, $\mathrm{AB}$ is not consistently stronger in people who are more dependent or use the drug more frequently. The obesity literature does not offer strong support to theoretical predictions because cross-sectional studies suggest that obesity is not robustly associated with elevated $\mathrm{AB}$ for food-related cues.

\section{Prediction 2: Is the Strength of AB a Good Predictor of Future Behavior, Specifically Drug Use and Food Intake, or the Consequences of That Behavior, Such as Changes in Body Weight?}

Several studies demonstrated that individual differences in $A B$ were positively correlated with individual differences in ad libitum food consumption that was measured immediately after assessment of AB (Nijs, Muris, et al., 2010; Werthmann, Renner et al., 2014; Werthmann, Roefs, Nederkoorn, \& Jansen, 2013; but see Hardman, Scott, Field, \& Jones, 2014). Two other studies investigated the association between $\mathrm{AB}$ for food and subsequent change in body weight and reported the predicted associations, although the findings were not robust because in both studies, only some measures of $\mathrm{AB}$ were predictive of body weight at some, but not all, follow-up assessments (Calitri, Pothos, Tapper, Brunstrom, \& Rogers, 2010; Werthmann et al., 2015). Regarding addiction 
studies, the evidence for predictive validity of $\mathrm{AB}$ is very inconsistent. Christiansen, Schoenmakers, and Field (2015) reviewed 15 prospective studies, the majority of which measured $\mathrm{AB}$ in clinical settings in patients who were receiving treatment at the time. Overall, there was no consistent prospective relationship between $\mathrm{AB}$ measured in clinical settings and relapse to drug use that occurred days, weeks or months later. Finally, two studies demonstrated that behavioral measures of $\mathrm{AB}$ were not predictive of future behavior, but patterns of brain activation during $\mathrm{AB}$ were predictive (Marhe, Waters, Van De Wetering, \& Franken, 2013; Yokum, Ng, \& Stice, 2011). These dissociations are intriguing, and further research is required to determine if they can be attributed to the relatively poor reliability of behavioral measures (Ataya et al., 2012; Van Bockstaele et al., 2014), or if patterns of brain activation associated with $\mathrm{AB}$ capture something qualitatively different to behavioral measures.

Overall, it appears that the predictive relationship between $\mathrm{AB}$ and future behavior is not robust, particularly when there is a long time interval between assessment of $\mathrm{AB}$ and changes in drug use or body weight. However, findings from a recent study (Marhe et al., 2013) suggest that $A B$ might predict behavior in the very near future. In this study, heroin-dependent patients who were undergoing detoxification completed a Stroop task on a mobile electronic device several times per day for 1 week. Analyses revealed that, in participants who relapsed during the study week, AB was particularly high just before relapse occurred. If this finding could be replicated and extended, the implication would be that $A B$ has a particularly close relationship with increased risk of relapse in the very near future, but its predictive validity is reduced as the delay between assessment of $\mathrm{AB}$ and the occurrence of relapse lengthens.

In summary, prospective studies suggest that there is no consistent relationship between $\mathrm{AB}$ and distal behavior, but $\mathrm{AB}$ may predict behavior that occurs in the near future. This is problematic for theoretical models that frame $\mathrm{AB}$ as an enduring "trait" characteristic that can predict a person's behavior in the distant future. One explanation for this pattern of findings is that motivational state fluctuates over time, which means that there is likely to be a mismatch between a person's motivational state when $A B$ is assessed (typically in the lab or clinic), and their motivational state when they actually consume the substance outside of the lab or clinic, which could be several hours, weeks, or months later.

\section{Prediction 3: Does AB Have a Causal Influence on Behavior and Subjective Craving?}

This prediction can be evaluated with reference to attentional bias modification (ABM) studies, in which $\mathrm{AB}$ is directly manipulated before subjective motivational states and behavior are assessed. These studies serve two purposes. First, they enable testing of theoretical predictions that increases in $\mathrm{AB}$ should influence motivational state and the consumption of drugs and food. Second, they represent a translational application of $\mathrm{AB}$ research, because $\mathrm{ABM}$ may prompt reductions in subjective craving and substance consumption. The majority of ABM studies used a modified visual probe task (MacLeod, Rutherford, Campbell, Ebsworthy, \& Holker, 2002) in which the location of visual probes was systematically varied so that participants were trained to either attend toward ("attend substance" groups) or away from ("avoid sub- stance" groups) a specific category of stimuli (e.g., food pictures), but $\mathrm{AB}$ was not manipulated in control groups.

ABM studies conducted with drug users were reviewed by Christiansen et al. (2015). Several studies investigated the effects of a single session of ABM for alcohol cues (three studies), smoking cues (three studies), or opiate cues (one study) on subjective craving and/or substance use. Some of these reported that ABM may have a causal influence on craving, because participants in attend substance groups reported increased alcohol craving (Field, Duka et al., 2007; Field \& Eastwood, 2005) or cigarette craving (Attwood, O’Sullivan, Leonards, Mackintosh, \& Munafò, 2008) after ABM, although these effects were limited to subgroups of participants in the later studies (Attwood et al., 2008; Field, Duka et al., 2007). Unfortunately, none of the studies that contrasted avoid substance with control conditions reported a reduction in craving after ABM (Attwood et al., 2008; Charles et al., 2015; Field, Duka et al., 2007; Field \& Eastwood, 2005; McHugh, Murray, Hearon, Calkins, \& Otto, 2010; Schoenmakers, Wiers, Jones, Bruce, \& Jansen, 2007). Of these seven studies, only one reported the predicted effects of ABM on consummatory behavior (Field \& Eastwood, 2005); this was not replicated in the other studies.

Subsequent studies investigated the effects of multiple sessions of $\mathrm{ABM}$ in patients who were trying to abstain from alcohol or tobacco. Two studies administered ABM in clinical settings to tobacco smokers, and both reported no effect on craving or relapse to smoking (Begh et al., 2015; Lopes, Pires, \& Bizarro, 2014). Findings from trials of $\mathrm{ABM}$ with problem drinkers are difficult to interpret given lack of an active control condition in two studies (Cox, Fadardi, Hosier \& Pothos, 2015; Fadardi \& Cox, 2009; see Wiers et al., 2015) and low statistical power and ambiguous findings in another (Schoenmakers et al., 2010).

More encouraging results were reported by McGeary, Meadows, Amir, and Gibb (2014). In their study, heavy drinking students who completed 4 weeks of avoid-alcohol ABM in their own homes reported drinking alcohol less frequently, compared to a control group. In another study (Kerst \& Waters, 2014), tobacco smokers (who were not attempting to quit) completed 15 sessions of $\mathrm{ABM}$ on a mobile device, together with craving measures, over 1 week. Compared to a control group, participants in the avoidsmoking group showed a reduction in $\mathrm{AB}$ and a corresponding reduction in subjective craving over the course of the week.

Werthmann, Jansen et al. (2015) reviewed studies that investigated the effects of ABM for food-related cues. The majority of studies measured participants' food intake after single sessions of attend-food or avoid-food manipulations, and most found the predicted effects: higher consumption of foods corresponding to pictures that were trained in the attend compared to the avoid groups (Kakoschke, Kemps, \& Tiggemann, 2014; Kemps, Tiggemann, \& Elford, 2015; Kemps, Tiggemann, Orr, \& Grear, 2014; Werthmann, Field, Roefs, Nederkoorn, \& Jansen, 2014). Although these findings are promising, interpretation is complicated because most studies contrasted the effects of attend-food and avoid food manipulations but did not include a control group, so it is unclear if the attend food ABM manipulation led to increased food intake, if the avoid food ABM manipulation led to reduced food intake, or both. Furthermore, two studies reported no change in either $A B$ or food intake after ABM (Boutelle, Kuckertz, Carlson, \& Amir, 2014; Hardman, Rogers, Etchells, Houstoun, \& Munafò, 2013). 
In summary, the evidence is consistent with the claim that experimentally induced $\mathrm{AB}$ may prompt an increase in subjective craving and/or consummatory behavior, an interpretation that is consistent with the theoretical predictions outlined above. However, it is less clear if experimentally reduced $A B$ leads to a reduction in craving or reduced consummatory behavior, particularly outside of the laboratory setting. Recent addiction studies suggest that multiple $\mathrm{ABM}$ sessions might prompt reductions in craving or changes in behavior, particularly if participants complete $\mathrm{ABM}$ on a computer at home, or on a mobile device as they go about their daily lives. Further studies are required to confirm these findings.

\section{Prediction 4: Is AB Indicative of Underlying Appetitive Motivational Processes?}

The final prediction shared by existing theories is that $A B$ is indicative of underlying appetitive motivational processes, and therefore it should be positively correlated with the strength of subjective craving or hunger. The available evidence supports this prediction. A meta-analysis of addiction studies conducted in the laboratory reported a robust, albeit weak $(r=.19)$ positive correlation between $\mathrm{AB}$ and craving (Field, Munafò, \& Franken, 2009), and a recent experience sampling study confirmed that $\mathrm{AB}$ and drug craving tend to co-occur in naturalistic settings outside of the laboratory (Waters, Marhe, \& Franken, 2012). Regarding AB for food-related cues, two recent narrative reviews (Doolan et al., 2014; Werthmann, Jansen et al., 2015) identified several studies that reported significant positive correlations between food-related $\mathrm{AB}$ and general hunger or foodspecific craving in the laboratory (Castellanos et al., 2009; Gearhardt, Treat, Hollingworth, \& Corbin, 2012; Graham, Hoover, Ceballos, \& Komogortsev, 2011; Mogg, Bradley, Hyare, \& Lee, 1998; Nijs, Franken, \& Muris, 2010; Nijs, Muris et al., 2010; Schmitz, Naumann, Trentowska, \& Svaldi, 2014; Tapper, Pothos, \& Lawrence, 2010; Werthmann, Roefs, Nederkoorn, \& Jansen, 2013; Werthmann et al., 2011) although this relationship was not observed in all studies (Hardman et al., 2014; Loeber, Grosshans, Herpertz, Kiefer, \& Herpertz, 2013; Loeber et al., 2012; Nummenmaa, Hietanen, Calvo, \& Hyönä, 2011).

Further evidence for an association between $\mathrm{AB}$ and subjective motivational states comes from studies that directly manipulated the motivational state before observing the effect on AB. As reviewed elsewhere (Field \& Cox, 2008; Field \& Franken, 2014), experimental manipulations such as alcohol administration, nicotine deprivation, negative mood induction and cue exposure led to increases in subjective craving that were accompanied by increases in AB (Bradley, Garner, Hudson, \& Mogg, 2007; Field, Mogg, \& Bradley, 2004, 2005; Field \& Powell, 2007; Field \& Quigley, 2009; Field, Rush, Cole, \& Goudie, 2007; Grant, Stewart, \& Birch, 2007; Ramirez, Monti, \& Colwill, 2015a, 2015b; Schoenmakers, Wiers, \& Field, 2008), although this was not seen in all studies (Eastwood, Bradley, Mogg, Tyler, \& Field, 2010; Mogg \& Bradley, 2002; Schoenmakers \& Wiers, 2010). Other experimental manipulations that reduced subjective craving also suggest correspondence between $\mathrm{AB}$ and craving: reductions in subjective craving accompanied by reduced $A B$ were seen after brief exercise
(Oh \& Taylor, 2013, 2014; Van Rensburg, Taylor, \& Hodgson, 2009), devaluation of alcoholic drinks by making them taste unpleasant (Rose, Brown, Field, \& Hogarth, 2013), and emotional reappraisal (Szasz, Szentagotai, \& Hofmann, 2012).

With regards to $\mathrm{AB}$ for food, an early study demonstrated that subjective hunger and $\mathrm{AB}$ increased after a period of fasting (Lavy \& Van den Hout, 1993). Subsequent experimental manipulations of fasting tended to confirm this finding (Castellanos et al., 2009; Channon \& Hayward, 1990; Nijs, Muris et al., 2010; Piech, Pastorino, \& Zald, 2010; Stockburger, Schmälzle, Flaisch, Bublatzky, \& Schupp, 2009; Placanica, Faunce, \& Soames Job, 2002), although not in all studies (Leland \& Pineda, 2006; Mogg et al., 1998). Subjective hunger has also been manipulated (up or down) in other ways, and these studies suggest close correspondence between hunger and $\mathrm{AB}$ after exposure to chocolate cues (Smeets, Roefs, \& Jansen, 2009), negative mood induction (Hepworth, Mogg, Brignell, \& Bradley, 2010; although see Werthmann, Renner et al., 2014), and after exercise (Oh \& Taylor, 2013, 2014).

In summary, there is compelling evidence that $\mathrm{AB}$ fluctuates alongside subjective craving or hunger, and that experimentally induced changes in these appetitive motivational states are accompanied by changes in $\mathrm{AB}$. This evidence is consistent with theoretical predictions that $\mathrm{AB}$ reflects an appetitive motivational process. These studies also illustrate an important point that has been alluded to in previous sections: withinsubject fluctuations in $\mathrm{AB}$ might be more important than between-groups differences. This could partly explain why differences in $\mathrm{AB}$ between users and nonusers of addictive drugs (e.g., heroin users vs. nonusers) appear robust, because, on average, subjective craving for heroin will be higher in users versus nonusers. However, within groups of people who regularly consume drugs (e.g., alcohol consumers) and food (i.e., everybody), AB may be closely associated with the current level of craving or hunger, respectively. This could obscure associations between $\mathrm{AB}$ measured in the laboratory and individual differences in substance consumption outside of the laboratory (, e.g., the number of alcoholic drinks or food calories consumed within a week), or the consequences of overconsumption such as obesity.

\section{The Roles of Aversive Motivation and Motivational Conflict}

The involvement of appetitive motivational processes in $\mathrm{AB}$ does not preclude the possibility that aversive motivational processes, and the conflict between appetitive and aversive motivational processes, might also be important. Both addiction (Miller, 1996) and obesity (Armstrong et al., 2011; Stroebe, Mensink, Aarts, Schut, \& Kruglanski, 2008) are characterized by motivational conflict (or ambivalence). Indeed, most people experience occasional conflict between enjoyment of food and the desire to maintain a healthy weight (De Ridder, Adriaanse, Evers, \& Verhoeven, 2014), particularly those who are obese (Andreyeva, Long, Henderson, \& Grode, 2010). Motivational conflict could be very important in the context of $\mathrm{AB}$, because when a person feels conflicted about a substance, stimuli associated with that substance may be evaluated as attractive and aversive, because they are desired but they also represent a 
threat to the goal of behavior change (Cacioppo, Gardner, \& Berntson, 1999). If this speculation is correct, one might expect to see very different patterns of $\mathrm{AB}$ for substance cues in people who experience motivational conflict about the substance versus, those who do not. Specifically, in people who experience motivational conflict, substance cues might be evaluated negatively and provoke concerns ("worry") about the problem behavior, and those people may also attempt to override their $\mathrm{AB}$ for substance-related cues in order to regulate their emotional response (Koole, 2009) or suppress subjective craving (Hofmann \& Van Dillen, 2012). Indeed, research in other domains has demonstrated that momentary goals can bias attention toward stimuli that are relevant to those goals, even when those stimuli compete with other motivationally salient stimuli (Cox, Klinger \& Fadardi, 2006; Vogt \& De Houwer, 2014; Vogt, De Houwer, Crombez, \& Van Damme, 2013), and some previous accounts claimed that both appetitive and aversive processes could contribute to $\mathrm{AB}$ in people who were attempting to control their behavior (Field \& Cox, 2008; Lee \& Shafran, 2004; Roefs, Houben, \& Werthmann, 2015; Werthmann, Jansen et al., 2015).

Careful consideration of the role of motivational conflict may explain some apparent inconsistencies in the existing AB literature. Alcohol-dependent patients who have received (or are still receiving) hospital treatment and are attempting to remain abstinent exhibit a pattern of $\mathrm{AB}$ that is qualitatively different from that seen in heavy drinkers who are not attempting to abstain or reduce their drinking, and who are not usually tested in hospital settings. As reviewed elsewhere (Field et al., 2013), studies that used the visual probe task demonstrated that alcohol-dependent patients had an AB for alcohol cues if those cues were presented briefly, but this switched to attentional avoidance when pictures were presented for half a second or longer. One interpretation (see Field et al., 2013) is that this "approach-avoidance" pattern is associated with the motivational conflict that dependent patients experience during treatment. Direct support for the notion that an approach-avoidance pattern of $\mathrm{AB}$ is associated with motivational conflict is provided by a recent study (Lee, Cho, \& Lee, 2014) in which problem drinkers with and without ambivalence (motivational conflict) viewed pairs of alcohol-related and matched neutral pictures while their eye movements were recorded. The conflicted drinkers tended to direct their gaze toward alcohol pictures at the beginning of each trial, but they directed their gaze away from the alcohol pictures at the end of the trial. Drinkers who were not conflicted about their drinking tended to maintain their gaze on alcohol pictures throughout each trial.

The observed approach-avoidance pattern of $\mathrm{AB}$ on the visual probe task may appear incompatible with findings from studies that used the modified Stroop, which revealed elevated $\mathrm{AB}$ for alcohol words in problem drinkers, regardless of whether or not they were tested in clinical settings and/or were attempting to remain abstinent at the time (Cox, Fadardi, \& Pothos, 2006). However, slower color-naming on the modified Stroop could reflect an aversive response to the stimuli, or a combination of appetitive and aversive responding, that is, ambivalence (Yiend, 2010). Consistent with this argument, Greenaway, Mogg, and Bradley (2012) found that, in a sample of pregnant women, the degree of Stroop interference for smok- ing words was associated with both appetitive (favorable attitudes to smoking) and aversive (fear of harm to the fetus) evaluations of smoking. Thus, when assessed with the modified Stroop task, AB in substance users who are attempting to remain abstinent may (at least partly) reflect aversive motivational processing of those words. The same may apply to ERP measures, which are equally sensitive to appetitive and aversive stimuli (Briggs \& Martin, 2009). As previously noted, ERPs in substance users are of greater magnitude when they are viewing substance cues, regardless of whether those individuals are seeking treatment (and motivated to remain abstinent), or not (Littel et al., 2012).

A similar approach-avoidance pattern of $\mathrm{AB}$ may be observed in obese participants who experience motivational conflict about food (see Roefs et al., 2015; Werthmann, Jansen et al., 2015), One study used an eye tracking task and demonstrated this approach-avoidance pattern of $\mathrm{AB}$ for food cues in obese participants who were concerned about their weight, relative to normal weight controls who were less concerned about their weight (Werthmann et al., 2011). Another study demonstrated attentional avoidance of food pictures in obese patients who were awaiting bariatric surgery (Giel et al., 2014). Even in people who are not obese, mindsets are likely to fluctuate between anticipated hedonic enjoyment of food and the anticipated (negative) health consequences of consuming unhealthy foods, and these fluctuations could lead to variation in the nature and magnitude of $\mathrm{AB}$ over time within individuals (see Meule et al., 2013; Werthmann, Jansen, \& Roefs, 2016). Unfortunately, very little is known about the association between $\mathrm{AB}$ for food and aversive responses to food-related stimuli that accompany fear about gaining weight, and this as an important topic for further investigation.

To summarize, the studies described in this section suggest that the motivational processes that contribute to $\mathrm{AB}$ in obesity and addiction may be more complicated than claimed by existing theories. Aversive processing of substance-related cues associated with motivational conflict regarding drugs or overeating could make an important contribution in addicted patients who are attempting to maintain abstinence, and in obese participants who are motivated to lose weight.

\section{Integration: Toward a New Theoretical Account of AB in Obesity and Addiction}

In this section, existing theories are integrated with observations made throughout this paper to generate a novel account of the role of $\mathrm{AB}$ in obesity and addiction. This account can explain findings that are incompatible with predictions made by existing theories. Figure 1 presents a schematic overview of the account, and its key features are described in the figure legend.

A key tenet of this account is that $\mathrm{AB}$ arises from momentary evaluations of substance cues: if those cues are evaluated positively, or negatively, or both simultaneously (ambivalence), then they will capture the attention. Importantly, the evaluation of substance-related cues is likely to vary from moment to moment depending on current motivational orientations to consume the substance or to refrain from consuming it. The proposed key role for stimulus evaluation in $\mathrm{AB}$ is informed by classic research on emotion and attention, which demonstrates 


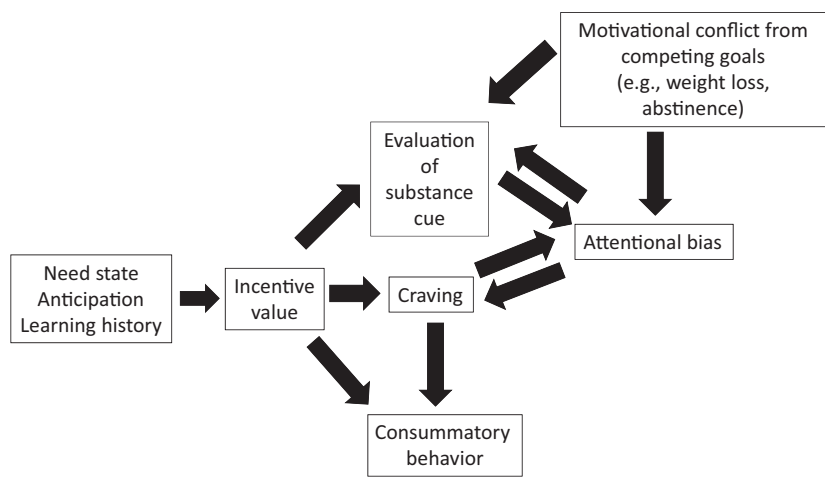

Figure 1. A model of the role of attentional bias in obesity and addiction. Note. Attentional bias for a substance-related cue arises when that cue is evaluated either positively or negatively, or both (ambivalence). Importantly, it is the overall strength of that evaluation, rather than its valence, that determines the magnitude of attentional bias (although this may depend on the task used; see text). Positive evaluations of substance-related cues arise as an output of the incentive value of the substance at that moment in time. Subjective craving and consummatory behavior are also outputs of the incentive value of the substance, which explains why attentional bias, cue evaluations, craving and proximal consummatory behavior tend to covary. Substance incentive value is itself determined by multiple factors including biological or emotional "need state" (e.g., caloric restriction, nicotine withdrawal), the perceived availability of the substance ("anticipation"), and the presence of environmental cues that have been paired with the substance ("learning history"), Negative evaluations of substance-related cues arise when people experience motivational conflict between the goal to consume the substance and the goal to control their behavior, such as a goal to lose weight or to abstain from drugs. We also suggest that, in these circumstances, people may attempt to override or control their attentional bias. The model also predicts reciprocal causal relationships between attentional bias and craving, that craving can increase the vigor with which consummatory behavior is pursued, and that attentional bias modification may change evaluations of substance-related cues. Finally, the model predicts an approach-avoidance pattern of attentional bias if cues are evaluated positively and negatively at the same time (i.e., ambivalence), although this pattern can only be detected when using the visual probe task with concurrent eye movement monitoring, and is not depicted in the figure. It is important to clarify that this is a model of attentional bias and its determinants and consequences, and we acknowledge that the processes depicted in the model (particularly substance incentive value and motivational conflict) can influence behavior through many different mechanisms, including but not limited to attentional bias.

that strongly valenced stimuli (both positive and negative) capture attention in proportion to the degree of physiological arousal that they evoke (see Lang, Bradley, \& Cuthbert, 1998). It is also consistent with theoretical accounts of $\mathrm{AB}$ for negatively valenced stimuli in healthy individuals and those with anxiety and depression, which claim that $\mathrm{AB}$ for those stimuli arises from strong negative evaluations and the increased arousal that accompanies those evaluations (see Yiend, 2010).

A further prediction is that the overall strength of the evaluation of a substance-related cue, rather than its valence (positive, negative, or both [ambivalent]), determines the magnitude of $\mathrm{AB}$ when it is assessed with the modified Stroop task or ERP measures. It may be possible to infer the valence of the evaluation when using the visual probe task with concurrent eye movement monitoring, with strong positive evaluations leading to a bias to maintain gaze on substance-related stimuli, and ambivalent evaluations leading to an approach-avoidance pattern, but this speculation awaits empirical testing. The claim that perceived valence of substance-related cues contributes to $\mathrm{AB}$ is supported by demonstrations that $\mathrm{AB}$ for substancerelated cues is accompanied by a tendency to perceive those cues as pleasant (Bradley, Field, Mogg, \& De Houwer, 2004; Brignell, Griffiths, Bradley, \& Mogg, 2009; Littel et al., 2012; Mogg, Bradley, Field, \& De Houwer, 2003; Nijs, Franken, \& Muris, 2008). In line with the previous discussion about motivational conflict, negative evaluations of substance-related cues should also contribute to $\mathrm{AB}$ for those cues, particularly in populations who experience motivational conflict. This prediction should be a priority for empirical testing.

What determines that a substance-related cue will be evaluated positively? Informed by existing accounts of motivated behavior (see Dickinson \& Balleine, 2010), the present account assigns a central role to the incentive value of the substance at that moment in time. Incentive value is itself determined by a combination of internal need states (e.g., caloric deprivation, nicotine withdrawal), the perceived availability of the substance ("anticipation"), and the presence of environmental cues that have been associated with that substance ("learning history"). Importantly, it is argued that the momentary incentive value of the substance yields two additional outputs, in addition to positive evaluations of substance cues: (a) a subjective output (craving or hunger); and (b) a behavioral output (consummatory behavior).

Given that substance incentive value fluctuates over time, the present account might explain the observation that $A B$ is imperfectly associated with between-groups differences in drug use or obesity, but it is closely associated with subjective motivational state and consummatory behavior that occurs in the near future. A further prediction that can be generated is that $\mathrm{AB}$ is not necessary to translate increased substance incentive value into behavior: if substance incentive value is high, a person would still consume the substance even if their $\mathrm{AB}$ could be blocked (if they were prevented from maintaining their attention on substance cues; see Hogarth \& Chase, 2013). Despite this, findings from the available ABM studies suggest that there are probably reciprocal causal relationships between the strength of $\mathrm{AB}$ and subjective craving. These reciprocal relationships could eventually cause craving to rise to such a level that it becomes "irresistible", and thereby increases the probability of engaging in consummatory behavior.

As detailed above, an important prediction is that substancerelated cues will be evaluated negatively or ambivalently in people who experience motivational conflict between desire to consume the substance and goals to change their behavior (e.g., limit food intake in order to lose weight, or stop drinking alcohol), and these negative evaluations will generate $A B$ for those cues. Consideration of this issue might account for the observed approach-avoidance pattern of $A B$ that is seen on the visual probe task in alcohol-dependent patients who are receiving treatment, and emerging evidence that a similar pattern is seen in obese patients who are trying to lose weight. It might also explain why studies that used the modified Stroop task or ERP measures revealed comparable patterns of $\mathrm{AB}$ in people who were attempting to change their behavior and those who were not, because appetitive and aversive responses to the cues 
yield equivalent patterns of $\mathrm{AB}$ on these measures. A related but distinct issue is that goals to control behavior and associated worry could prompt strategic attempts to control or override $\mathrm{AB}$, but these strategies could paradoxically increase $\mathrm{AB}$, or at least some components of it (Littel \& Franken, 2011; Meule et al., 2013; Yiend, 2010). Therefore, motivational conflict may influence $\mathrm{AB}$ through two mechanisms, an automatic mechanism that operates through altered evaluations of those cues, and a strategic mechanism in which people attempt to change their AB directly.

This account also suggests possible mechanisms through which ABM might indirectly influence appetitive behavior. First, given that stimuli can be devalued if attention is repeatedly shifted away from them (Fenske \& Raymond, 2006), one possibility is that repeated sessions of ABM may alter evaluations of substance stimuli. In turn, this could reduce the capacity of representations of that substance to evoke $\mathrm{AB}$, craving, and motivated behavior. If so, this would place $\mathrm{ABM}$ alongside other novel behavioral interventions for addiction and overeating such as cue avoidance training (Wiers, Eberl, Rinck, Becker, \& Lindenmeyer, 2011) and inhibitory control training (Houben, Nederkoorn, Wiers, \& Jansen, 2011; Veling, van Koningsbruggen, Aarts, \& Stroebe, 2014), which may also change behavior through stimulus devaluation (Veling, Holland, \& van Knippenberg, 2008). An alternative mechanism, which could operate alongside the first, is that ABM could interfere with the rumination and elaboration process that causes craving to escalate, and thereby reduce the likelihood that subjective craving could cross the threshold needed to trigger consummatory behavior (Franken, 2003; Hofmann \& Van Dillen, 2012). According to this explanation, ABM may be able to prevent craving from increasing in strength.

To summarize, the account of $\mathrm{AB}$ described here and depicted in Figure 1 may account for findings in the AB literature that are problematic for existing theories. First, the contention that $\mathrm{AB}$ is determined by momentary evaluations of substancerelated cues might account for inconsistent between-groups differences in AB. This is because within-subject differences in evaluations of substance-related cues at that moment in time may be much more influential determinants of $\mathrm{AB}$ than more stable between-subjects differences, so the former tend to mask the effects of the latter. Second, the model might account for the lack of predictive validity of $\mathrm{AB}$ for future behavior when the interval between the two is long, because the stimulus evaluations that underlie $\mathrm{AB}$ at one time and one treatment context (e.g., in an addiction clinic) are likely to be very different from the stimulus evaluations that underlie $\mathrm{AB}$ several days, weeks or months later, and when assessed in a different context (e.g., outside the clinic, when drugs are available). Third, the model may account for the inconsistent effects of $\mathrm{ABM}$ on behavior, because $A B M$ is unlikely to have a dramatic effect on the strong incentive value attributed to substances that determines $A B$, craving and behavior. In other words, ABM may target an output of the motivational processes that determine behavior, but it may not directly influence the underlying motivational processes. Finally, although $\mathrm{AB}$ is robustly associated with subjective craving and hunger and is therefore at least partly a marker of appetitive motivational processes, it is important to note that ostensibly "appetitive" disorders such as obesity and addiction are characterized by motivational conflict about the problem behavior. These aversive motivational processes could also contribute to $\mathrm{AB}$ for substance-related stimuli, and consideration of this issue might explain the characteristics and underlying determinants of $\mathrm{AB}$ in people who are addicted or obese and are motivated to change their behavior.

\section{Novel Predictions and Suggestions for Future Research}

The model outlined in Figure 1 generates the following predictions that can be empirically tested in future research.

\section{The Predictive Validity of AB for Future Behavior}

According to the model, both $\mathrm{AB}$ and behavior are outputs of the incentive value of the substance at that moment in time, which is itself influenced by several factors. Therefore, the predictive validity of $\mathrm{AB}$ should be maximal when it is measured soon before the behavior of interest, and in the same context. Experience sampling methods may be particularly suitable for testing this prediction (see Marhe et al., 2013).

Related to this, the model does not predict any association between $\mathrm{AB}$ and future behavior when there is a mismatch between substance incentive value when $A B$ is measured, and substance incentive value when behavior is measured. In most of the prospective addiction studies, $\mathrm{AB}$ was measured in contexts in which substance incentive value was likely to be very low; for example, in alcohol-dependent patients who were receiving inpatient detoxification treatment. This is a mismatch with the likely incentive value of alcohol later, when the person was outside of the treatment setting and alcohol was available to consume.

\section{The Relationship Between AB for Substance Cues and the Perceived Valence of Those Cues}

Similar patterns of AB should be seen in people who experience motivational conflict about their behavior (e.g., obese people who want to lose weight, alcohol-dependent patients who want to abstain) and those who do not, when assessed with the modified Stroop task or ERP measures. This is because these tasks cannot distinguish between $\mathrm{AB}$ that is determined by positive and negative evaluations of substance-related cues. However, group differences in $\mathrm{AB}$ should be apparent on a visual probe task with concurrent eye movement monitoring, as we would expect to see an approach-avoidance pattern of $A B$ in the former group but a more consistent $\mathrm{AB}$ in the latter group. The model makes novel predictions about the evaluative judgments that underlie $\mathrm{AB}$ in these different groups. In people who experience motivational conflict, $\mathrm{AB}$ should be predicted by the strength of negative rather than positive evaluations of substance cues. Whereas, in people who are not motivated to change their behavior, the strength of positive evaluations of substance cues should be the best predictor. Related to this point, researchers should be mindful of the possibility that some participants could evaluate substance cues negatively, and consider this when preparing stimulus materials for $\mathrm{AB}$ research. For example, a photograph of a slice of pizza that is "swimming" in grease may be intended to evoke an appetitive re- 
sponse, but obese people who are attempting to lose weight could evaluate it negatively.

\section{AB Should Be Sensitive to the Perceived Valence of Substance Cues}

To test this prediction, evaluative conditioning procedures could be used to pair substance-related pictures with negative images, which should alter the valence of the substance pictures (Houben, Havermans, \& Wiers, 2010). When assessed with a visual probe task with concurrent eye movement monitoring, $\mathrm{AB}$ for the substance pictures should change in line with changes in their perceived valence.

\section{More Comprehensive Investigations of the Effects of AB on Goal-Directed Behavior}

The model predicts that substance cues will be able to increase consummatory behavior even if $\mathrm{AB}$ to those cues is blocked by preventing people from focusing their attention on them (see Hogarth, Dickinson, Janowski, Nikitina, \& Duka, 2008; Hogarth, Dickinson, \& Duka, 2009). However, if participants can maintain their attention on those cues before they are able to consume the substance, they will consume more compared to a group that was not given the opportunity to express $\mathrm{AB}$, and this effect will be mediated by elevated craving.

\section{The Mechanisms Through Which ABM Influences Behavior}

The model suggests two indirect mechanisms through which ABM may influence consummatory behavior. One possibility is that participants who receive multiple sessions of "avoid substance" ABM would report a reduction in the perceived positive valence of cues used during ABM (Veling et al., 2008), which would in turn mediate the effects of $\mathrm{ABM}$ on behavior. An alternative prediction is that ABM "blunts" subjective craving, that is, prevents it from increasing in strength, and this blunting effect mediates the effect of ABM on behavior. These are important questions for future research, and it is also important to investigate if the effectiveness of ABM depends on the context in which it is administered (in the clinic vs. elsewhere), as has been reported for ABM for anxiety disorders (Linetzky, Pergamin-Hight, Pine, \& Bar-Haim, 2015; see also Cristea, Kok, \& Cuijpers, 2015).

\section{Clinical Implications and Limitations}

The theoretical synthesis presented here has implications for clinicians and health psychologists. Most importantly, AB is reframed as primarily an output of the motivational processes that determine behavior, rather than a direct determinant of that behavior itself. The most obvious implication of this is pessimism regarding the potential of $\mathrm{ABM}$ as a behavior change intervention. Two mechanisms are described through which $\mathrm{ABM}$ might lead to behavior change, but neither is likely to have a substantial impact. First, if ABM alters the perceived valence of substance-related cues, this effect is likely to be very small and would probably be dwarfed by other influences on substance incentive value such as biological "need" (e.g., caloric restriction), perceived availability, and negative mood. Second, if ABM exerts its effects through suppression of craving, one implication is that participants should complete ABM sessions only when they are experiencing strong cravings, because ABM administered when craving is low is unlikely to be effective (see Kerst $\&$ Waters, 2014). Despite this pessimistic picture, it is important to note that research on ABM is in its infancy, and results from adequately powered clinical trials with appropriate control conditions are awaited before a definitive judgment is made on its clinical potential.

A further implication is that momentary fluctuations in $\mathrm{AB}$ may serve as an "early warning signal" for temptations to consume substances in the near future, a signal that may precede increases in subjective craving or desire (Marhe et al., 2013; Waters et al., 2012). If the findings reported by Marhe et al. (2013) could be replicated and extended to other populations (e.g., people who are overweight and are attempting to lose weight), there is the potential to develop assessments of $A B$ into smartphone apps that people could complete throughout the day. If $\mathrm{AB}$ increases it would be a warning signal that they should take action to cope with imminent temptation, such as reminding themselves of their goals (e.g., to lose weight, or to avoid alcohol) and perhaps reinforce any coping skills that they are currently using.

Finally, the model suggests that measurement of $A B$ in clinical settings as people receive treatment may not be a useful predictor of future behavior, particularly for addictions. It may be possible to harness the predictive validity of brain activity that is associated with $\mathrm{AB}$ to identify individuals who are likely to need additional help to achieve their goals, or to identify whether the development of attentional avoidance is associated with motivation to change behavior as treatment progresses (see Morgenstern, Naqvi, Debellis, \& Breiter, 2013).

\section{Summary and Conclusions}

This critical discussion of the literature on $\mathrm{AB}$ in obesity and addiction suggests that the stability of $\mathrm{AB}$ and its influence on behavior have been overestimated, and the contributions of current substance incentive value and motivational conflict regarding the behavior have been underestimated. According to the theoretical synthesis described in this paper, $\mathrm{AB}$ is reframed as an output of the evaluation of substance-related cues, something that is itself determined by both the current incentive value of the substance as well as motivational conflict arising from goals to control behavior. This account suggests that $\mathrm{AB}$ does not have a direct causal influence on behavior, but it permits the possibility that it may have an indirect influence, and specifies the psychological mechanisms that may underlie this. Further research is required to confirm or refute predictions generated by this account, and to enable its modification in the future.

\section{References}

Andreyeva, T., Long, M. W., Henderson, K. E., \& Grode, G. M. (2010). Trying to lose weight: Diet strategies among Americans with overweight or obesity in 1996 and 2003. Journal of the American Dietetic Association, 110, 535-542. http://dx.doi.org/10.1016/j.jada.2009.12.029

Appelhans, B. M., French, S. A., Pagoto, S. L., \& Sherwood, N. E. (2016). Managing temptation in obesity treatment: A neurobehavioral model of 
intervention strategies. Appetite, 96, 268-279. http://dx.doi.org/10.1016/ j.appet.2015.09.035

Armstrong, M. J., Mottershead, T. A., Ronksley, P. E., Sigal, R. J., Campbell, T. S., \& Hemmelgarn, B. R. (2011). Motivational interviewing to improve weight loss in overweight and/or obese patients: A systematic review and meta-analysis of randomized controlled trials. Obesity Reviews, 12, 709-723. http://dx.doi.org/10.1111/j.1467-789x .2011.00892.x

Ataya, A. F., Adams, S., Mullings, E., Cooper, R. M., Attwood, A. S., \& Munafò, M. R. (2012). Internal reliability of measures of substancerelated cognitive bias. Drug and Alcohol Dependence, 121, 148-151. http://dx.doi.org/10.1016/j.drugalcdep.2011.08.023

Attwood, A. S., O'Sullivan, H., Leonards, U., Mackintosh, B., \& Munafò, M. R. (2008). Attentional bias training and cue reactivity in cigarette smokers. Addiction, 103, 1875-1882. http://dx.doi.org/10.1111/j.13600443.2008.02335.x

Baker, T. B., Morse, E., \& Sherman, J. E. (1986). The motivation to use drugs: A psychobiological analysis of urges. Nebraska Symposium on Motivation, 34, 257-323.

Begh, R., Munafò, M. R., Shiffman, S., Ferguson, S. G., Nichols, L., Mohammed, M. A., . . A Aveyard, P. (2015). Lack of attentional retraining effects in cigarette smokers attempting cessation: A proof of concept double-blind randomized controlled trial. Drug and Alcohol Dependence, 149, 158-165. http://dx.doi.org/10.1016/j.drugalcdep.2015.01 .041

Berridge, K. C. (2009). 'Liking' and 'wanting' food rewards: Brain substrates and roles in eating disorders. Physiology \& Behavior, 97, 537550. http://dx.doi.org/10.1016/j.physbeh.2009.02.044

Boutelle, K. N., Kuckertz, J. M., Carlson, J., \& Amir, N. (2014). A pilot study evaluating a one-session attention modification training to decrease overeating in obese children. Appetite, 76, 180-185. http://dx.doi .org/10.1016/j.appet.2014.01.075

Bradley, B., Field, M., Mogg, K., \& De Houwer, J. (2004). Attentional and evaluative biases for smoking cues in nicotine dependence: Component processes of biases in visual orienting. Behavioural Pharmacology, 15, 29-36. http://dx.doi.org/10.1097/00008877-200402000-00004

Bradley, B. P., Garner, M., Hudson, L., \& Mogg, K. (2007). Influence of negative affect on selective attention to smoking-related cues and urge to smoke in cigarette smokers. Behavioural Pharmacology, 18, 255-263. http://dx.doi.org/10.1097/FBP.0b013e328173969b

Briggs, K. E., \& Martin, F. H. (2009). Affective picture processing and motivational relevance: Arousal and valence effects on ERPs in an oddball task. International Journal of Psychophysiology, 72, 299-306. http://dx.doi.org/10.1016/j.jpsycho.2009.01.009

Brignell, C., Griffiths, T., Bradley, B. P., \& Mogg, K. (2009). Attentional and approach biases for pictorial food cues. Influence of external eating. Appetite, 52, 299-306. http://dx.doi.org/10.1016/j.appet.2008.10.007

Cacioppo, J. T., Gardner, W. L., \& Berntson, G. G. (1999). The affect system has parallel and integrative processing components: Form follows function. Journal of Personality and Social Psychology, 76, 839855. http://dx.doi.org/10.1037/0022-3514.76.5.839

Calitri, R., Pothos, E. M., Tapper, K., Brunstrom, J. M., \& Rogers, P. J. (2010). Cognitive biases to healthy and unhealthy food words predict change in BMI. Obesity, 18, 2282-2287. http://dx.doi.org/10.1038/oby .2010 .78

Castellanos, E. H., Charboneau, E., Dietrich, M. S., Park, S., Bradley, B. P., Mogg, K., \& Cowan, R. L. (2009). Obese adults have visual attention bias for food cue images: Evidence for altered reward system function. International Journal of Obesity, 33, 1063-1073. http://dx.doi .org/10.1038/ijo.2009.138

Cecil, J., Dalton, M., Finlayson, G., Blundell, J., Hetherington, M., \& Palmer, C. (2012). Obesity and eating behaviour in children and adolescents: Contribution of common gene polymorphisms. International
Review of Psychiatry, 24, 200-210. http://dx.doi.org/10.3109/09540261 2012.685056

Channon, S., \& Hayward, A. (1990). The effect of short-term fasting on processing of food cues in normal subjects. International Journal of Eating Disorders, 9, 447-452. http://dx.doi.org/10.1002/1098108X(199007)9:4<447::AID-EAT2260090411>3.0.CO;2-0

Charles, M., Wellington, C. E., Mokrysz, C., Freeman, T. P., O'Ryan, D., \& Curran, H. V. (2015). Attentional bias and treatment adherence in substitute-prescribed opiate users. Addictive Behaviors, 46, 100-105. http://dx.doi.org/10.1016/j.addbeh.2015.03.017

Christiansen, P., Mansfield, R., Duckworth, J., Field, M., \& Jones, A. (2015). Internal reliability of the alcohol-related visual probe task is increased by utilizing personalized stimuli and eye-tracking. Drug and Alcohol Dependence, 155, 170-174. http://dx.doi.org/10.1016/j .drugalcdep.2015.07.672

Christiansen, P., Schoenmakers, T. M., \& Field, M. (2015). Less than meets the eye: Reappraising the clinical relevance of attentional bias in addiction. Addictive Behaviors, 44, 43-50.

Cisler, J. M., \& Koster, E. H. W. (2010). Mechanisms of attentional biases towards threat in anxiety disorders: An integrative review. Clinical Psychology Review, 30, 203-216. http://dx.doi.org/10.1016/j.cpr.2009 .11 .003

Cox, W. M., Fadardi, J. S., Hosier, S. G., \& Pothos, E. M. (2015). Differential effects and temporal course of attentional and motivational training on excessive drinking. Experimental and Clinical Psychopharmacology, 23, 445-454. http://dx.doi.org/10.1037/pha0000038

Cox, W. M., Fadardi, J. S., \& Pothos, E. M. (2006). The Addiction-Stroop test: Theoretical considerations and procedural recommendations. Psychological Bulletin, 132, 443-476. http://dx.doi.org/10.1037/0033-2909 132.3.443

Cox, W. M., Klinger, E., \& Fadardi, J. S. (2006). Motivational basis of cognitive determinants of addiction. In M. Munafo \& I. P. Albery (Eds.), Cognition and addiction (pp. 101-116). New York, NY: Oxford University Press.

Cristea, I. A., Kok, R. N., \& Cuijpers, P. (2015). Efficacy of cognitive bias modification interventions in anxiety and depression: Meta-analysis. The British Journal of Psychiatry, 206, 7-16. http://dx.doi.org/10.1192/bjp .bp.114.146761

de Ridder, D., Adriaanse, M., Evers, C., \& Verhoeven, A. (2014). Who diets? Most people and especially when they worry about food. Appetite, 80, 103-108. http://dx.doi.org/10.1016/j.appet.2014.05.011

Dickinson, A., \& Balleine, B. T. (2010). The cognitive/motivational interface. In M. L. Kringelbach \& K. C. Berridge (Eds.), Pleasures of the brain (pp. 74-84). New York, NY: Oxford University Press.

Doolan, K. J., Breslin, G., Hanna, D., \& Gallagher, A. M. (2014). Attentional bias to food-related visual cues: Is there a role in obesity? Proceedings of the Nutrition Society, 74, 37-45. http://dx.doi.org/10 .1017/S002966511400144X

Eastwood, B., Bradley, B., Mogg, K., Tyler, E., \& Field, M. (2010). Investigating the effects of a craving induction procedure on cognitive bias in cannabis users. Addiction Research \& Theory, 18, 97-109. http://dx.doi.org/10.3109/16066350802699328

Fadardi, J. S., \& Cox, W. M. (2009). Reversing the sequence: Reducing alcohol consumption by overcoming alcohol attentional bias. Drug and Alcohol Dependence, 101, 137-145. http://dx.doi.org/10.1016/j drugalcdep.2008.11.015

Fenske, M. J., \& Raymond, J. E. (2006). Affective influences of selective attention. Current Directions in Psychological Science, 15, 312-316. http://dx.doi.org/10.1111/j.1467-8721.2006.00459.x

Field, M., \& Cox, W. M. (2008). Attentional bias in addictive behaviors: A review of its development, causes, and consequences. Drug and Alcohol Dependence, 97, 1-20. http://dx.doi.org/10.1016/j.drugalcdep .2008.03.030 
Field, M., Duka, T., Eastwood, B., Child, R., Santarcangelo, M., \& Gayton, M. (2007). Experimental manipulation of attentional biases in heavy drinkers: Do the effects generalize? Psychopharmacology, 192, 593608. http://dx.doi.org/10.1007/s00213-007-0760-9

Field, M., \& Eastwood, B. (2005). Experimental manipulation of attentional bias increases the motivation to drink alcohol. Psychopharmacology, 183, 350-357. http://dx.doi.org/10.1007/s00213-005-0202-5

Field, M., \& Franken, I. H. A. (2014). Attentional bias to drug cues. In I. P. Stolerman \& L. H. Price (Eds.), Encyclopedia of psychopharmacology (pp. 1-5). Berlin, Germany: Springer.

Field, M., Marhe, R., \& Franken, I. H. A. (2014). The clinical relevance of attentional bias in substance use disorders. CNS Spectrums, 19, 225-230. http://dx.doi.org/10.1017/S1092852913000321

Field, M., Mogg, K., \& Bradley, B. P. (2004). Eye movements to smokingrelated cues: Effects of nicotine deprivation. Psychopharmacology, 173, 116-123. http://dx.doi.org/10.1007/s00213-003-1689-2

Field, M., Mogg, K., \& Bradley, B. P. (2005). Alcohol increases cognitive biases for smoking cues in smokers. Psychopharmacology, 180, 63-72. http://dx.doi.org/10.1007/s00213-005-2251-1

Field, M., Mogg, K., Mann, B., Bennett, G. A., \& Bradley, B. P. (2013). Attentional biases in abstinent alcoholics and their association with craving. Psychology of Addictive Behaviors, 27, 71-80. http://dx.doi .org/10.1037/a0029626

Field, M., Munafò, M. R., \& Franken, I. H. A. (2009). A meta-analytic investigation of the relationship between attentional bias and subjective craving in substance abuse. Psychological Bulletin, 135, 589-607. http://dx.doi.org/10.1037/a0015843

Field, M., \& Powell, H. (2007). Stress increases attentional bias for alcohol cues in social drinkers who drink to cope. Alcohol and Alcoholism, 42, 560-566. http://dx.doi.org/10.1093/alcalc/agm064

Field, M., \& Quigley, M. (2009). Mild stress increases attentional bias in social drinkers who drink to cope: A replication and extension. Experimental and Clinical Psychopharmacology, 17, 312-319. http://dx.doi .org/10.1037/a0017090

Field, M., Rush, M., Cole, J., \& Goudie, A. (2007). The smoking Stroop and delay discounting in smokers: Effects of environmental smoking cues. Journal of Psychopharmacology, 21, 603-610. http://dx.doi.org/ 10.1177/0269881106070995

Franken, I. H. A. (2003). Drug craving and addiction: Integrating psychological and neuropsychopharmacological approaches. Progress in Neuro-Psychopharmacology \& Biological Psychiatry, 27, 563-579. http://dx.doi.org/10.1016/S0278-5846(03)00081-2

Gearhardt, A. N., Treat, T. A., Hollingworth, A., \& Corbin, W. R. (2012). The relationship between eating-related individual differences and visual attention to foods high in added fat and sugar. Eating Behaviors, 13, 371-374. http://dx.doi.org/10.1016/j.eatbeh.2012.07.004

Giel, K. E., Rieber, N., Enck, P., Friederich, H. C., Meile, T., Zipfel, S., \& Teufel, M. (2014). Effects of laparoscopic sleeve gastrectomy on attentional processing of food-related information: Evidence from eyetracking. Surgery for Obesity and Related Diseases, 10, 277-282. http:// dx.doi.org/10.1016/j.soard.2013.09.012

Graham, R., Hoover, A., Ceballos, N. A., \& Komogortsev, O. (2011). Body mass index moderates gaze orienting biases and pupil diameter to high and low calorie food images. Appetite, 56, 577-586. http://dx.doi.org/ 10.1016/j.appet.2011.01.029

Grant, V. V., Stewart, S. H., \& Birch, C. D. (2007). Impact of positive and anxious mood on implicit alcohol-related cognitions in internally motivated undergraduate drinkers. Addictive Behaviors, 32, 2226-2237. http://dx.doi.org/10.1016/j.addbeh.2007.02.012

Greenaway, R., Mogg, K., \& Bradley, B. P. (2012). Attentional bias for smoking-related information in pregnant women: Relationships with smoking experience, smoking attitudes and perceived harm to foetus. Addictive Behaviors, 37, 1025-1028. http://dx.doi.org/10.1016/j.addbeh .2012.04.005
Hardman, C. A., Rogers, P. J., Etchells, K. A., Houstoun, K. V. E., \& Munafò, M. R. (2013). The effects of food-related attentional bias training on appetite and food intake. Appetite, 71, 295-300. http://dx.doi .org/10.1016/j.appet.2013.08.021

Hardman, C. A., Scott, J., Field, M., \& Jones, A. (2014). To eat or not to eat. The effects of expectancy on reactivity to food cues. Appetite, 76 , 153-160. http://dx.doi.org/10.1016/j.appet.2014.02.005

Hepworth, R., Mogg, K., Brignell, C., \& Bradley, B. P. (2010). Negative mood increases selective attention to food cues and subjective appetite. Appetite, 54, 134-142. http://dx.doi.org/10.1016/j.appet.2009.09.019

Hofmann, W., \& Van Dillen, L. (2012). Desire: The new hot spot in self-control research. Current Directions in Psychological Science, 21 , 317-322. http://dx.doi.org/10.1177/0963721412453587

Hogarth, L., \& Chase, H. W. (2013). Vulnerabilities underlying human drug dependence: Goal valuation versus habit learning. In M. Haselgrove \& L. Hogarth (Eds.), Clinical applications of learning theory (pp. 75-101). New York, NY: Psychology Press.

Hogarth, L., Dickinson, A., \& Duka, T. (2009). Detection versus sustained attention to drug cues have dissociable roles in mediating drug seeking behavior. Experimental and Clinical Psychopharmacology, 17, 21-30. http://dx.doi.org/10.1037/a0014957

Hogarth, L., Dickinson, A., Janowski, M., Nikitina, A., \& Duka, T. (2008) The role of attentional bias in mediating human drug-seeking behaviour Psychopharmacology, 201, 29-41. http://dx.doi.org/10.1007/s00213008-1244-2

Houben, K., Havermans, R. C., \& Wiers, R. W. (2010). Learning to dislike alcohol: Conditioning negative implicit attitudes toward alcohol and its effect on drinking behavior. Psychopharmacology, 211, 79-86. http:// dx.doi.org/10.1007/s00213-010-1872-1

Houben, K., Nederkoorn, C., Wiers, R. W., \& Jansen, A. (2011). Resisting temptation: Decreasing alcohol-related affect and drinking behavior by training response inhibition. Drug and Alcohol Dependence, 116, 132136. http://dx.doi.org/10.1016/j.drugalcdep.2010.12.011

Kakoschke, N., Kemps, E., \& Tiggemann, M. (2014). Attentional bias modification encourages healthy eating. Eating Behaviors, 15, 120-124. http://dx.doi.org/10.1016/j.eatbeh.2013.11.001

Kavanagh, D. J., Andrade, J., \& May, J. (2005). Imaginary relish and exquisite torture: The elaborated intrusion theory of desire. Psychological Review, 112, 446-467. http://dx.doi.org/10.1037/0033-295X.112.2 .446

Kemps, E., Tiggemann, M., \& Elford, J. (2015). Sustained effects of attentional re-training on chocolate consumption. Journal of Behavior Therapy and Experimental Psychiatry. 49(Pt A), 94-100. http://dx.doi org/10.1016/j.jbtep.2014.12.001

Kemps, E., Tiggemann, M., Orr, J., \& Grear, J. (2014). Attentional retraining can reduce chocolate consumption. Journal of Experimental Psychology: Applied, 20, 94-102. http://dx.doi.org/10.1037/xap0000005

Kerst, W. F., \& Waters, A. J. (2014). Attentional retraining administered in the field reduces smokers' attentional bias and craving. Health Psychology, 33, 1232-1240. http://dx.doi.org/10.1037/a0035708

Koole, S. (2009). The psychology of emotion regulation: An integrative review. Cognition and Emotion, 23, 4-41. http://dx.doi.org/10.1080/ 02699930802619031

Lang, P. J., Bradley, M. M., \& Cuthbert, B. N. (1998). Emotion, motivation, and anxiety: Brain mechanisms and psychophysiology Biological Psychiatry, 44, 1248-1263. http://dx.doi.org/10.1016/ S0006-3223(98)00275-3

Lavy, E. H., \& Van den Hout, M. A. (1993). Attentional bias for appetitive cues: Effects of fasting in normal subjects. Behavioural and Cognitive Psychotherapy, 21, 297-310. http://dx.doi.org/10.1017/S1352465800011632

Lee, M., \& Shafran, R. (2004). Information processing biases in eating disorders. Clinical Psychology Review, 24, 215-238. http://dx.doi.org/ 10.1016/j.cpr.2003.10.004 
Lee, S., Cho, S., \& Lee, J. H. (2014). Approach-avoidance pattern of visual attention in hazardous drinkers with ambivalence. Addictive Behaviors, 39, 669-676. http://dx.doi.org/10.1016/j.addbeh.2013.12.001

Leeman, R. F., Robinson, C. D., Waters, A. J., \& Sofuoglu, M. (2014). A critical review of the literature on attentional bias in cocaine use disorder and suggestions for future research. Experimental and Clinical Psychopharmacology, 22, 469-483. http://dx.doi.org/10.1037/a0037806

Leland, D. S., \& Pineda, J. A. (2006). Effects of food-related stimuli on visual spatial attention in fasting and nonfasting normal subjects: Behavior and electrophysiology. Clinical Neurophysiology, 117, 67-84. http://dx.doi.org/10.1016/j.clinph.2005.09.004

Linetzky, M., Pergamin-Hight, L., Pine, D. S., \& Bar-Haim, Y. (2015). Quantitative evaluation of the clinical efficacy of attention bias modification treatment for anxiety disorders. Depression and Anxiety, 32, 383-391. http://dx.doi.org/10.1002/da.22344

Littel, M., Euser, A. S., Munafò, M. R., \& Franken, I. H. A. (2012). Electrophysiological indices of biased cognitive processing of substance-related cues: A meta-analysis. Neuroscience and Biobehavioral Reviews, 36, 1803-1816. http://dx.doi.org/10.1016/j.neubiorev 2012.05 .001

Littel, M., \& Franken, I. H. A. (2011). Intentional modulation of the late positive potential in response to smoking cues by cognitive strategies in smokers. PLoS ONE, 6(11), e27519. http://dx.doi.org/10.1371/journal .pone.0027519

Loeber, S., Grosshans, M., Herpertz, S., Kiefer, F., \& Herpertz, S. C. (2013). Hunger modulates behavioral disinhibition and attention allocation to food-associated cues in normal-weight controls. Appetite, 71, 32-39. http://dx.doi.org/10.1016/j.appet.2013.07.008

Loeber, S., Grosshans, M., Korucuoglu, O., Vollmert, C., Vollstädt-Klein, S., Schneider, S., . . Kiefer, F. (2012). Impairment of inhibitory control in response to food-associated cues and attentional bias of obese participants and normal-weight controls. International journal of obesity, 36, 1334-1339. http://dx.doi.org/10.1038/ijo.2011.184

Lopes, F. M., Pires, A. V., \& Bizarro, L. (2014). Attentional bias modification in smokers trying to quit: A longitudinal study about the effects of number of sessions. Journal of Substance Abuse Treatment, 47, 50-57. http://dx.doi.org/10.1016/j.jsat.2014.03.002

MacLeod, C., Rutherford, E., Campbell, L., Ebsworthy, G., \& Holker, L. (2002). Selective attention and emotional vulnerability: Assessing the causal basis of their association through the experimental manipulation of attentional bias. Journal of Abnormal Psychology, 111, 107-123. http://dx.doi.org/10.1037/0021-843X.111.1.107

Marhe, R., Waters, A. J., van de Wetering, B. J. M., \& Franken, I. H. A. (2013). Implicit and explicit drug-related cognitions during detoxification treatment are associated with drug relapse: An ecological momentary assessment study. Journal of Consulting and Clinical Psychology, 81, 1-12. http://dx.doi.org/10.1037/a0030754

McGeary, J. E., Meadows, S. P., Amir, N., \& Gibb, B. E. (2014). Computer-delivered, home-based, attentional retraining reduces drinking behavior in heavy drinkers. Psychology of Addictive Behaviors, 28, 559-562. http://dx.doi.org/10.1037/a0036086

McHugh, R. K., Murray, H. W., Hearon, B. A., Calkins, A. W., \& Otto, M. W. (2010). Attentional bias and craving in smokers: The impact of a single attentional training session. Nicotine \& Tobacco Research, 12, 1261-1264. http://dx.doi.org/10.1093/ntr/ntq171

Meule, A., Kübler, A., \& Blechert, J. (2013). Time course of electrocortical food-cue responses during cognitive regulation of craving. Frontiers in Psychology, 4, 669. http://dx.doi.org/10.3389/fpsyg.2013.00669

Miller, W. R. (1996). Motivational interviewing: Research, practice, and puzzles. Addictive Behaviors, 21, 835-842. http://dx.doi.org/10.1016/ 0306-4603(96)00044-5

Mogg, K., \& Bradley, B. P. (2002). Selective processing of smokingrelated cues in smokers: Manipulation of deprivation level and compar- ison of three measures of processing bias. Journal of Psychopharmacology, 16, 385-392. http://dx.doi.org/10.1177/026988110201600416

Mogg, K., Bradley, B. P., Field, M., \& De Houwer, J. (2003). Eye movements to smoking-related pictures in smokers: Relationship between attentional biases and implicit and explicit measures of stimulus valence. Addiction, 98, 825-836. http://dx.doi.org/10.1046/j.1360-0443 2003.00392.x

Mogg, K., Bradley, B. P., Hyare, H., \& Lee, S. (1998). Selective attention to food-related stimuli in hunger: Are attentional biases specific to emotional and psychopathological states, or are they also found in normal drive states? Behaviour Research and Therapy, 36, 227-237. http://dx.doi.org/10.1016/S0005-7967(97)00062-4

Mogg, K., Field, M., \& Bradley, B. P. (2005). Attentional and approach biases for smoking cues in smokers: An investigation of competing theoretical views of addiction. Psychopharmacology, 180, 333-341. http://dx.doi.org/10.1007/s00213-005-2158-x

Morgenstern, J., Naqvi, N. H., Debellis, R., \& Breiter, H. C. (2013). The contributions of cognitive neuroscience and neuroimaging to understanding mechanisms of behavior change in addiction. Psychology of Addictive Behaviors, 27, 336-350. http://dx.doi.org/10.1037/a0032435

Nijs, I. M. T., \& Franken, I. H. A. (2012). Attentional processing of food cues in overweight and obese individuals. Current Obesity Reports, 1, 106-113. http://dx.doi.org/10.1007/s13679-012-0011-1

Nijs, I. M. T., Franken, I. H. A., \& Muris, P. (2008). Food cue-elicited brain potentials in obese and healthy-weight individuals. Eating Behaviors, 9, 462-470. http://dx.doi.org/10.1016/j.eatbeh.2008.07.009

Nijs, I. M. T., Franken, I. H. A., \& Muris, P. (2010). Food-related Stroop interference in obese and normal-weight individuals: Behavioral and electrophysiological indices. Eating Behaviors, 11, 258-265. http://dx .doi.org/10.1016/j.eatbeh.2010.07.002

Nijs, I. M. T., Muris, P., Euser, A. S., \& Franken, I. H. A. (2010) Differences in attention to food and food intake between overweight/ obese and normal-weight females under conditions of hunger and satiety. Appetite, 54, 243-254. http://dx.doi.org/10.1016/j.appet.2009.11 .004

Nummenmaa, L., Hietanen, J. K., Calvo, M. G., \& Hyönä, J. (2011). Food catches the eye but not for everyone: A BMI-contingent attentional bias in rapid detection of nutriments. PLOS ONE, 6(5), e19215. http://dx.doi .org/10.1371/journal.pone.0019215

Oh, H., \& Taylor, A. H. (2013). A brisk walk, compared with being sedentary, reduces attentional bias and chocolate cravings among regular chocolate eaters with different body mass. Appetite, 71, 144-149. http:// dx.doi.org/10.1016/j.appet.2013.07.015

Oh, H., \& Taylor, A. H. (2014). Self-regulating smoking and snacking through physical activity. Health Psychology, 33, 349-359. http://dx.doi .org/10.1037/a0032423

Piech, R. M., Pastorino, M. T., \& Zald, D. H. (2010). All I saw was the cake. Hunger effects on attentional capture by visual food cues. Appetite, 54, 579-582. http://dx.doi.org/10.1016/j.appet.2009.11.003

Placanica, J. L., Faunce, G. J., \& Soames Job, R. F. (2002). The effect of fasting on attentional biases for food and body shape/weight words in high and low Eating Disorder Inventory scorers. International Journal of Eating Disorders, 32, 79-90. http://dx.doi.org/10.1002/eat.10066

Polich, J. (2007). Updating P300: An integrative theory of P3a and P3b. Clinical Neurophysiology, 118, 2128-2148. http://dx.doi.org/10.1016/j .clinph.2007.04.019

Ramirez, J. J., Monti, P. M., \& Colwill, R. M. (2015a). Alcohol-cue exposure effects on craving and attentional bias in underage collegestudent drinkers. Psychology of Addictive Behaviors, 29, 317-322. http://dx.doi.org/10.1037/adb0000028

Ramirez, J. J., Monti, P. M., \& Colwill, R. M. (2015b). Brief and extended alcohol-cue-exposure effects on craving and attentional bias. Experimental and Clinical Psychopharmacology, 23, 159-167. http://dx.doi.org/ 10.1037/pha0000018 
Robinson, T. E., \& Berridge, K. C. (1993). The neural basis of drug craving: An incentive-sensitization theory of addiction. Brain Research Reviews, 18, 247-291. http://dx.doi.org/10.1016/0165-0173(93)90013-P

Roefs, A., Houben, K., \& Werthmann, J. (2015). Desire for food and the power of mind. In W. Hofmann \& L. F. Nordgren (Eds.), The psychology of desire (pp. 323-346). New York, NY: Guilford Press.

Rose, A. K., Brown, K., Field, M., \& Hogarth, L. (2013). The contributions of value-based decision-making and attentional bias to alcohol-seeking following devaluation. Addiction, 108, 1241-1249. http://dx.doi.org/10 .1111 add. 12152

Schmitz, F., Naumann, E., Trentowska, M., \& Svaldi, J. (2014). Attentional bias for food cues in binge eating disorder. Appetite, 80, 70-80. http://dx.doi.org/10.1016/j.appet.2014.04.023

Schoenmakers, T. M., de Bruin, M., Lux, I. F. M., Goertz, A. G., Van Kerkhof, D. H. A. T., \& Wiers, R. W. (2010). Clinical effectiveness of attentional bias modification training in abstinent alcoholic patients. Drug and Alcohol Dependence, 109, 30-36. http://dx.doi.org/10.1016/j .drugalcdep.2009.11.022

Schoenmakers, T. M., \& Wiers, R. W. (2010). Craving and attentional bias respond differently to alcohol priming: A field study in the pub. European Addiction Research, 16, 9-16. http://dx.doi.org/10.1159/ 000253859

Schoenmakers, T., Wiers, R. W., \& Field, M. (2008). Effects of a low dose of alcohol on cognitive biases and craving in heavy drinkers. Psychopharmacology, 197, 169-178. http://dx.doi.org/10.1007/s00213-0071023-5

Schoenmakers, T., Wiers, R. W., Jones, B. T., Bruce, G., \& Jansen, A. T. M. (2007). Attentional re-training decreases attentional bias in heavy drinkers without generalization. Addiction, 102, 399-405. http:// dx.doi.org/10.1111/j.1360-0443.2006.01718.x

Schupp, H. T., Cuthbert, B. N., Bradley, M. M., Hillman, C. H., Hamm, A. O., \& Lang, P. J. (2004). Brain processes in emotional perception: Motivated attention. Cognition and Emotion, 18, 593-611. http://dx.doi .org/10.1080/02699930341000239

Smeets, E., Roefs, A., \& Jansen, A. (2009). Experimentally induced chocolate craving leads to an attentional bias in increased distraction but not in speeded detection. Appetite, 53, 370-375. http://dx.doi.org/10 1016/j.appet.2009.07.020

Stockburger, J., Schmälzle, R., Flaisch, T., Bublatzky, F., \& Schupp, H. T. (2009). The impact of hunger on food cue processing: An event-related brain potential study. NeuroImage, 47, 1819-1829. http://dx.doi.org/10 .1016/j.neuroimage.2009.04.071

Stroebe, W., Mensink, W., Aarts, H., Schut, H., \& Kruglanski, A. W. (2008). Why dieters fail: Testing the goal conflict model of eating. Journal of Experimental Social Psychology, 44, 26-36. http://dx.doi .org/10.1016/j.jesp.2007.01.005

Szasz, P. L., Szentagotai, A., \& Hofmann, S. G. (2012). Effects of emotion regulation strategies on smoking craving, attentional bias, and task persistence. Behaviour Research and Therapy, 50, 333-340. http://dx .doi.org/10.1016/j.brat.2012.02.010

Tapper, K., Pothos, E. M., \& Lawrence, A. D. (2010). Feast your eyes: Hunger and trait reward drive predict attentional bias for food cues. Emotion, 10, 949-954. http://dx.doi.org/10.1037/a0020305

Van Bockstaele, B., Verschuere, B., Tibboel, H., De Houwer, J., Crombez, G., \& Koster, E. H. (2014). A review of current evidence for the causal impact of attentional bias on fear and anxiety. Psychological Bulletin, 140, 682-721. http://dx.doi.org/10.1037/a0034834

Van Rensburg, K. J., Taylor, A., \& Hodgson, T. (2009). The effects of acute exercise on attentional bias towards smoking-related stimuli during temporary abstinence from smoking. Addiction, 104, 1910-1917. http://dx.doi.org/10.1111/j.1360-0443.2009.02692.x

Veling, H., Holland, R. W., \& van Knippenberg, A. (2008). When approach motivation and behavioral inhibition collide: Behavior regulation through stimulus devaluation. Journal of Experimental Social Psychology, 44, 1013-1019. http://dx.doi.org/10.1016/j.jesp.2008.03.004

Veling, H., van Koningsbruggen, G. M., Aarts, H., \& Stroebe, W. (2014). Targeting impulsive processes of eating behavior via the Internet. Effects on body weight. Appetite, 78, 102-109. http://dx.doi.org/10.1016/ j.appet.2014.03.014

Vogt, J., \& De Houwer, J. (2014). Emotion regulation meets emotional attention: The influence of emotion suppression on emotional attention depends on the nature of the distracters. Emotion, 14, 840-845. http:// dx.doi.org/10.1037/a0037399

Vogt, J., De Houwer, J., Crombez, G., \& Van Damme, S. (2013). Competing for attentional priority: Temporary goals versus threats. Emotion, 13, 587-598. http://dx.doi.org/10.1037/a0027204

Volkow, N. D., \& Wise, R. A. (2005). How can drug addiction help us understand obesity? Nature Neuroscience, 8, 555-560. http://dx.doi.org/ $10.1038 / \mathrm{nn} 1452$

Vollstädt-Klein, S., Loeber, S., Winter, S., Leménager, T., von der Goltz, C., Dinter, C., . . Kiefer, F. (2011). Attention shift towards smoking cues relates to severity of dependence, smoking behavior and breath carbon monoxide. European Addiction Research, 17, 217-224. http://dx .doi.org/10.1159/000327775

Waters, A. J., Marhe, R., \& Franken, I. H. A. (2012). Attentional bias to drug cues is elevated before and during temptations to use heroin and cocaine. Psychopharmacology, 219, 909-921. http://dx.doi.org/10 .1007/s00213-011-2424-z

Werthmann, J., Field, M., Roefs, A., Nederkoorn, C., \& Jansen, A. (2014). Attention bias for chocolate increases chocolate consumption-An attention bias modification study. Journal of Behavior Therapy and Experimental Psychiatry, 45, 136-143. http://dx.doi.org/10.1016/j.jbtep 2013.09.009

Werthmann, J., Jansen, A., \& Roefs, A. (2015). Worry or craving? A selective review of evidence for food-related attention biases in obese individuals, eating-disorder patients, restrained eaters and healthy samples. Proceedings of the Nutrition Society, 74, 99-114. http://dx.doi.org/ 10.1017/S0029665114001451

Werthmann, J., Jansen, A., \& Roefs, A. (2016). Make up your mind about food: A healthy mindset attenuates attention for high-calorie food in restrained eaters. Appetite, 105, 53-59. http://dx.doi.org/10.1016/j.appet 2016.05.005

Werthmann, J., Jansen, A., Vreugdenhil, A. C., Nederkoorn, C., Schyns, G., \& Roefs, A. (2015). Food through the child's eye: An eye-tracking study on attentional bias for food in healthy-weight children and children with obesity. Health Psychology, 34, 1123-1132. http://dx.doi.org/10 1037/hea0000225

Werthmann, J., Renner, F., Roefs, A., Huibers, M. J. H., Plumanns, L., Krott, N., \& Jansen, A. (2014). Looking at food in sad mood: Do attention biases lead emotional eaters into overeating after a negative mood induction? Eating Behaviors, 15, 230-236. http://dx.doi.org/10 .1016/j.eatbeh.2014.02.001

Werthmann, J., Roefs, A., Nederkoorn, C., \& Jansen, A. (2013). Desire lies in the eyes: Attention bias for chocolate is related to craving and self-endorsed eating permission. Appetite, 70, 81-89. http://dx.doi.org/ 10.1016/j.appet.2013.06.087

Werthmann, J., Roefs, A., Nederkoorn, C., Mogg, K., Bradley, B. P., \& Jansen, A. (2011). Can(not) take my eyes off it: Attention bias for food in overweight participants. Health Psychology, 30, 561-569. http://dx doi.org/10.1037/a0024291

Werthmann, J., Roefs, A., Nederkoorn, C., Mogg, K., Bradley, B. P., \& Jansen, A. (2013). Attention bias for food is independent of restraint in healthy weight individuals-an eye tracking study. Eating Behaviors, 14 397-400. http://dx.doi.org/10.1016/j.eatbeh.2013.06.005

Wiers, R. W., Eberl, C., Rinck, M., Becker, E. S., \& Lindenmeyer, J. (2011). Retraining automatic action tendencies changes alcoholic patients' approach bias for alcohol and improves treatment outcome. 
Psychological Science, 22, 490-497. http://dx.doi.org/10.1177/ 0956797611400615

Wiers, R. W., Houben, K., Fadardi, J. S., van Beek, P., Rhemtulla, M., \& Cox, W. M. (2015). Alcohol cognitive bias modification training for problem drinkers over the web. Addictive Behaviors, 40, 21-26. http:// dx.doi.org/10.1016/j.addbeh.2014.08.010

Yiend, J. (2010). The effects of emotion on attention: A review of attentional processing of emotional information. Cognition and Emotion, 24, 3-47. http://dx.doi.org/10.1080/02699930903205698
Yokum, S., Ng, J., \& Stice, E. (2011). Attentional bias to food images associated with elevated weight and future weight gain: An fMRI study. Obesity, 19, 1775-1783. http://dx.doi.org/10.1038/oby.2011.168

Received March 3, 2015

Revision received May 27, 2016

Accepted May 27, 2016 